\title{
CUIR: EXPOSIÇÃO INDEPENDENTE
}

\author{
Pedro Oliveira e Silva SAMPAIO \\ Simone de Oliveira MOURA
}

\begin{abstract}
RESUMO
"CUIR" é uma proposição; uma exposição transviada realizada no Espaço Casulo Cultural durante maio de 2017, originada do desejo de ação genuína de reconfigurar imagens e possibilitar novos olhares sobre a arte que estava sendo feita em Belém por jovens artistas paraenses, o presente texto apresenta reflexões curatoriais e de ações políticas no campo das artes como possibilidade para discussões relacionadas a gênero e sexualidade. Os trabalhos artísticos apresentados confrontam as estruturas identitárias normativas, e se localizam nesse existir - resistir - que está na fronteira, ou para além dela. Diferente de programas multiculturais bem intencionados, onde as diferenças tanto sexuais, de gênero e raciais são toleradas ou apreciadas como meras curiosidades exóticas, a exposição CUIR estaria inserida muito mais em um processo de apresentação das diferenças como evidência da instabilidade e precariedade das identidades instituídas. Colocando para debate as formas como o outro é constituído, se é questionado as estreitas relações do eu com o outro. "A diferença deixaria de estar lá fora, do outro lado, alheia ao sujeito, e seria compreendida como indispensável para a existência do próprio sujeito: ela estaria dentro, integrando e constituindo o eu" (Louro, 2001. p.550). Ao se falar de uma educação cuir ligada a arte não seria suficiente denunciar a negação e repressão para os que operam fora da norma regente, e sim desconstruir o processo pelo qual alguns sujeitos se tornam normalizados e outros marginalizados. Sendo possível ser utilizada como uma maneira de entender o próprio corpo, construções e afirmações identitárias e suas relações e expressões sociais.Partindo de um relato de experiência do período de maio de 2017 este artigo é uma reconfiguração do artigo defendido para a Graduação em Artes Visuais e Tecnologia da Imagem da UNAMA - Universidade da Amazônia.
\end{abstract}

Palavras-chave: Queer. Arte. Educação. Cuir.

\section{CUIR: INDEPENDENT EXPOSURE}

"CUIR" is a proposition; a transposed exhibition held at the Espaço Cocoulo Cultural during May 2017, originated from the desire for genuine action to reconfigure images and enable new insights into the art that was being performed in Belém by young artists from Pará, this text presents curatorial reflections and political actions in the field of the arts as a possibility for discussions related to gender and sexuality. The artistic works presented confront normative identity structures, and are located in this exist - resist - that is on the border, or beyond. Unlike well-intentioned multicultural programs, where differences in sexual, gender and race are tolerated or appreciated as mere exotic curiosities, the CUIR exposition would be inserted much more into a process of presenting differences as evidence of instability and precariousness of established identities. Placing for debate the ways in which the other is constituted, if the close relations of the self with the other are questioned. "The difference would cease to be outside, on the other side, unrelated to the subject, and would be understood as indispensable for the existence of the subject himself: it would be inside, integrating and constituting the self" (Louro, 2001, p.550). When talking about an education linked to art it would not be enough to denounce denial and repression for those who operate outside the regent norm, but to deconstruct the process by which some subjects become normalized and others marginalized. It is possible to be used as a way of understanding one's own body, constructions and identity affirmations and their relations and social expressions. Starting from an experience report from the period of May 2017, this article is a reconfiguration of the article defended for the Graduation in Visual Arts and Image Technology of UNAMA - University of the Amazon.
\end{abstract}

Keywords: Queer. Art. Education. Cuir.
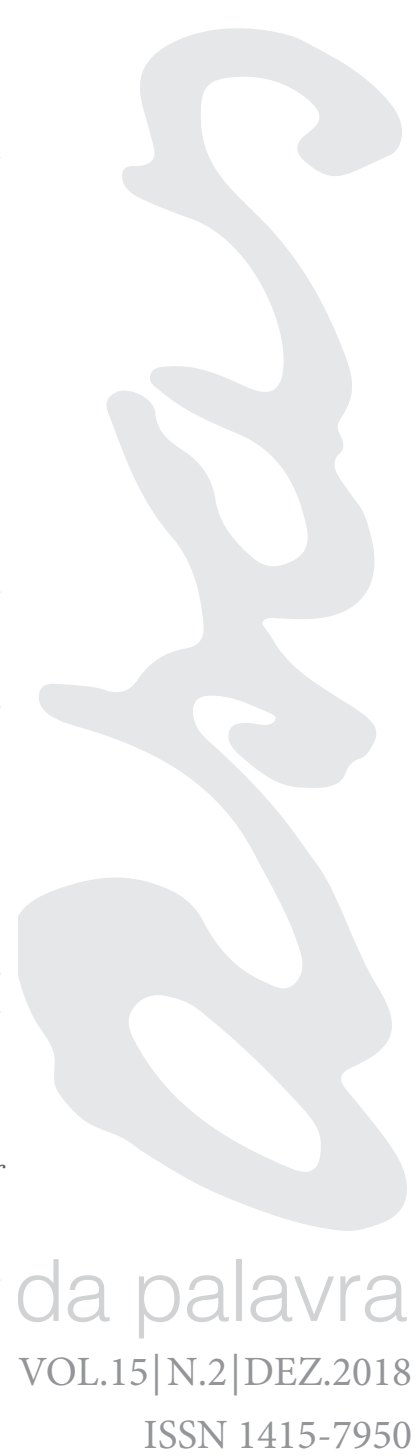


\section{CUIR: EXPOSICIÓN INDEPENDIENTE}

\section{RESUMEN}

"CUIR" es una proposición; una exposición transviada realizada en el Espacio Casulo Cultural durante mayo de 2017, originada del deseo de acción genuina de reconfigurar imágenes y posibilitar nuevas miradas sobre el arte que estaba siendo realizado en Belém por jóvenes artistas paraenses, el presente texto presenta reflexiones curatoriales y de acciones políticas en el campo de las artes como posibilidad para discusiones relacionadas con género y sexualidad. Los trabajos artísticos presentados enfrentan las estructuras identitarias normativas, y se ubican en ese existir - resistir que está en la frontera, o más allá de ella. A diferencia de programas multiculturales bien intencionados, donde las diferencias tanto sexuales, de género y raciales son toleradas o apreciadas como meras curiosidades exóticas, la exposición CUIR estar inserta mucho más en un proceso de presentación de las diferencias como evidencia de la inestabilidad y precariedad de las identidades instituidas. Poniendo para debate las formas como el otro está constituido, si se cuestiona las estrechas relaciones del yo con el otro. "La diferencia dejaría de estar allá afuera, del otro lado, ajena al sujeto, y sería comprendida como indispensable para la existencia del propio sujeto: ella estaría dentro, integrando y constituyendo el yo" (Louro, 2001. p.550). Al hablar de una educación cuidando el arte no sería suficiente denunciar la negación y represión para los que operan fuera de la norma regente, sino desconstruir el proceso por el cual algunos sujetos se vuelven normalizados y otros marginados. Siendo posible ser utilizada como una manera de entender el propio cuerpo, construcciones y afirmaciones identitarias y sus relaciones y expresiones sociales. A partir de un relato de experiencia del período de mayo de 2017 este artículo es una reconfiguración del artículo defendido para la Graduación en Artes Visuales y Tecnología de la Imagen de la UNAMA - Universidad de la Amazonia.

Palabras clave: Queer. Art. Educación. Cuir.

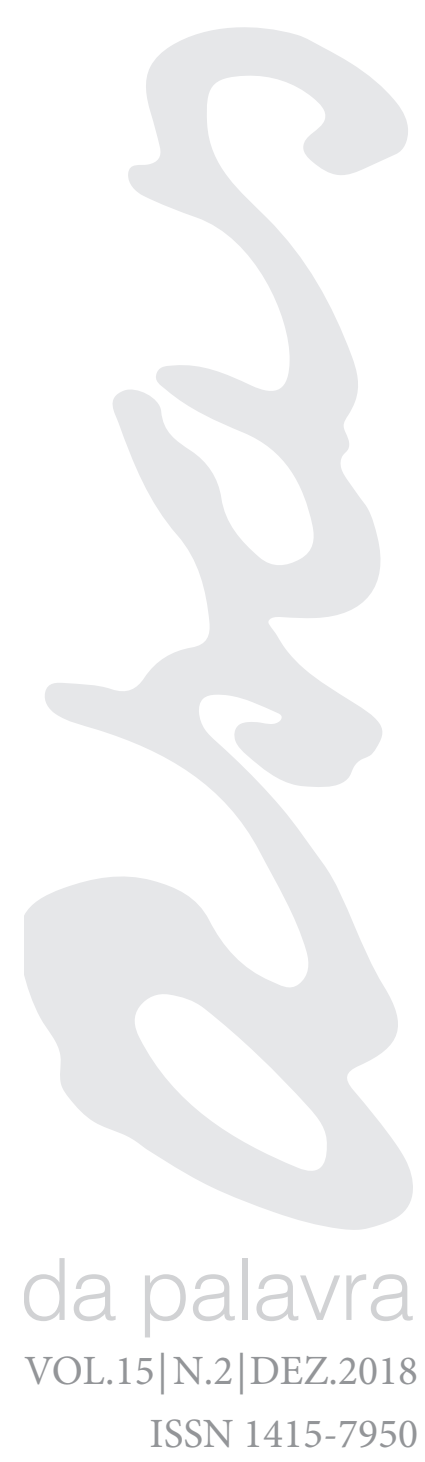




\title{
INTRODUÇÃO
}

A tradução dada para queer no português é comumente "estranho", o que não dá conta do significado total que a palavra em inglês carrega. Poderíamos talvez traduzir como transviado, o que atravessa os padrões, fora da norma; ou viado, como o insulto que é comumente usado no inglês. Teoria queer seria então o equivalente a uma teoria cu ou bicha, para causar o desconforto que o queer em outras terras causa.

O cuir surge como um ponto de interrogação, um repensar desse conhecimento fixado por uma ordem heteronormativa, trata-se de uma pedagogia que "sugere o questionamento, a desnaturalização e a incerteza como estratégias férteis e criativas para pensar qualquer dimensão da existência" (LOURO, 2004, p.52).

Tais estudos percebem a exigência que a nossa sociedade faz de uma suposta coerência entre sexo-gênero-desejo e prática sexual como uma imposição, uma coerção sobre os corpos. Como discutir esses temas então sem reforçar os binarismos vigentes?

Tão espalhada tem sido a mancha dispersa da crise do homo/ heterossexual que discutir quaisquer desses indices em qualquer contexto, sem uma análise anti-homofóbica, acabaria, talvez, por perpetuar compulsões implícitas em cada um deles sem o saber. Para qualquer questão moderna de sexualidade, o par conhecimento/ignorância é mais do que simples parte de uma cadeia metonímica de tais binarismos. (A EPISTEMOLOGIA DO ARMÁRIO, 1993, p.29).

A proposta de uma educação através da cultura visual é essencial para o deslocamento do estudo de agentes heteronormativos, masculinos, brancos e ocidentais, ainda predominantes nesse meio. O reconhecimento de identidades que fogem a uma visão hegemônica ainda é tímido nos relatos históricos artísticos, fazendo surgir a questão: onde estão presentes esses corpos?

Expor (-se) então, é um ato de vulnerabilidade e resistência. Dado que as estruturas da sociedade da forma como foi organizada privilegia apenas o lado heteronormativo, e se todos têm o direito à liberdade, que corpos são permitidos e que espaços temos para ocupação/tráfego para aqueles fora do espectro heterossexual cisgênero?

\begin{abstract}
Escola, currículos, educadoras e educadores não conseguem se situar fora dessa história. Mostram-se, quase sempre, perplexos, desafiados por questões para as quais pareciam ter, até pouco tempo atrás, respostas seguras e estáveis. Agora as certezas escapam, os modelos mostram-se inúteis, as fórmulas são inoperantes. Mas é impossivel estancar as questões. Não há como ignorar as 'novas' práticas, os 'novos' sujeitos, suas contestações ao estabelecido. A vocação normalizadora da Educação vê-se ameaçada. O anseio pelo cânone e pelas metas confíveis é abalado. (LOURO, 2001. p.542)
\end{abstract}

Uma exposição de arte que se propõe cuir, é para além de um passeio artístico, é uma ferramenta educacional e política. Exercitar o discurso subversivo sem sofrer o ato violento e coercitivo que a máquina de opressão e manipulação institucional impõe aos corpos é expandir a noção de identidade, para além do ato de resumir a categoria de indivíduo a só um aspecto, mostrando como categorias como homem, mulher ou homossexual podem ser mais do que comumente se é esperado de cada um.

A má interpretação sobre performatividade de gênero é essa: que gênero é uma escolha, ou que gênero é um papel, ou que gênero é a construção na qual nos colocamos, como se botássemos uma roupa de manhã, que existe 'um' que precede o gênero, um que vai até o armário de gêneros e escolhe com deliberação que gênero será hoje. (A JOURNAL OF LESBIAN AND GAY STUDIES, novembro, 1993, p.21). 
Organizar a própria exposição de arte trouxe responsabilidades e inúmeras possibilidades de troca e interação. Entre tantas escolhas, foi preciso limitar os pontos centrais que formariam a exposição, e investir em uma curadoria que permitisse liberdade de intervenção nas obras para solidificar o que viria a se tornar a CUIR. Posso colocar os pontos que fundamentaram a elaboração da exposição como sendo os seguintes:

- Nenhuma obra seria enviada formalmente pelos artistas

- As imagens seriam primeiramente selecionadas da internet, para depois serem autorizadas o uso na exposição

- Todas as obras poderiam ser modificadas caso houvesse necessidade

- Impressões e escolhas de dimensão e papel seriam de minha responsabilidade

- Tudo seria planejado com baixo orçamento, visto que a exposição seria autofinanciada

- Identidade visual marcada por uma estética digital, origem de todas as imagens.

Se os processos artísticos pensados para a exposição fossem bem sucedidos, dariam conta de evidenciar a diversidade das identidades, sem se limitar ao modelo de transmissão de papel de gênero já configurada em suas expectativas binárias e rasas. É o retrato configurando o corpo político como protagonista do próprio discurso. Representações pessoais do eu, apresentam um sujeito com suas próprias narrativas, autossuficiente e carregado de expressão.

No estilo faça você mesmo, sem edital nem patrocínio, de autocusteio e por vontade deliberada de fazer arte, nenhuma decisão ou escolha como curador atropelou ou se apropriou do outro como meio para um discurso que não fosse honesto e genuíno, sendo o papel de curador empregado muito mais de um agente cultural que possibilita espaços para encontros, trocas e ações espontâneas.

\section{ARTE CUIR: POSSIBILIDADES DISCURSIVAS}

O contato com algumas obras foi crucial para a primeira semente geradora da CUIR. A primeira delas sendo Alice de Rafael Bqueer, que me despertou o olhar para toda a angústia de se buscar algum sentido em meio ao caos. O impacto do corpo negro de Rafael travestido de Alice (Figura 1) sobre o lixo é inegável. Quantas cenas e vivências de violência estão presentes no cotidiano amazônico, entre maravilhas e realidades, paisagens opressoras e decadentes? Quantos resistem e seguem seu caminho em meio a lama assim como Alice, que segue desbravando um outro mundo ainda que procura por si mesma?

Outras imagens também foram fundamentais para o surgimento da exposição, pois foi a partir da associação delas que o pensamento para a CUIR foi se solidificando, sendo elas três ilustrações de Tarcísio Gabriel e uma fotografia de Lucas Barros.

As ilustrações de Tarcísio (Figura 2) com seus corpos disformes como que trocados de lugar, criam uma tensão do desmembramento metafórico para a construção de uma identidade ainda em formação. Os traços de nanquim são precisos e as figuras são vazadas, mas, ainda que sem um fundo, parecem estáveis e sólidas.

A fragilidade dos corpos nus também aparece no trabalho de Lucas Barros (Figura 3), mas, aqui o masculino aparece desprovido de sua masculinidade, os genitais estão escondidos e seu performar na fotografia é afeminado. Índios andrógenos em meio às árvores contemplam para além do 


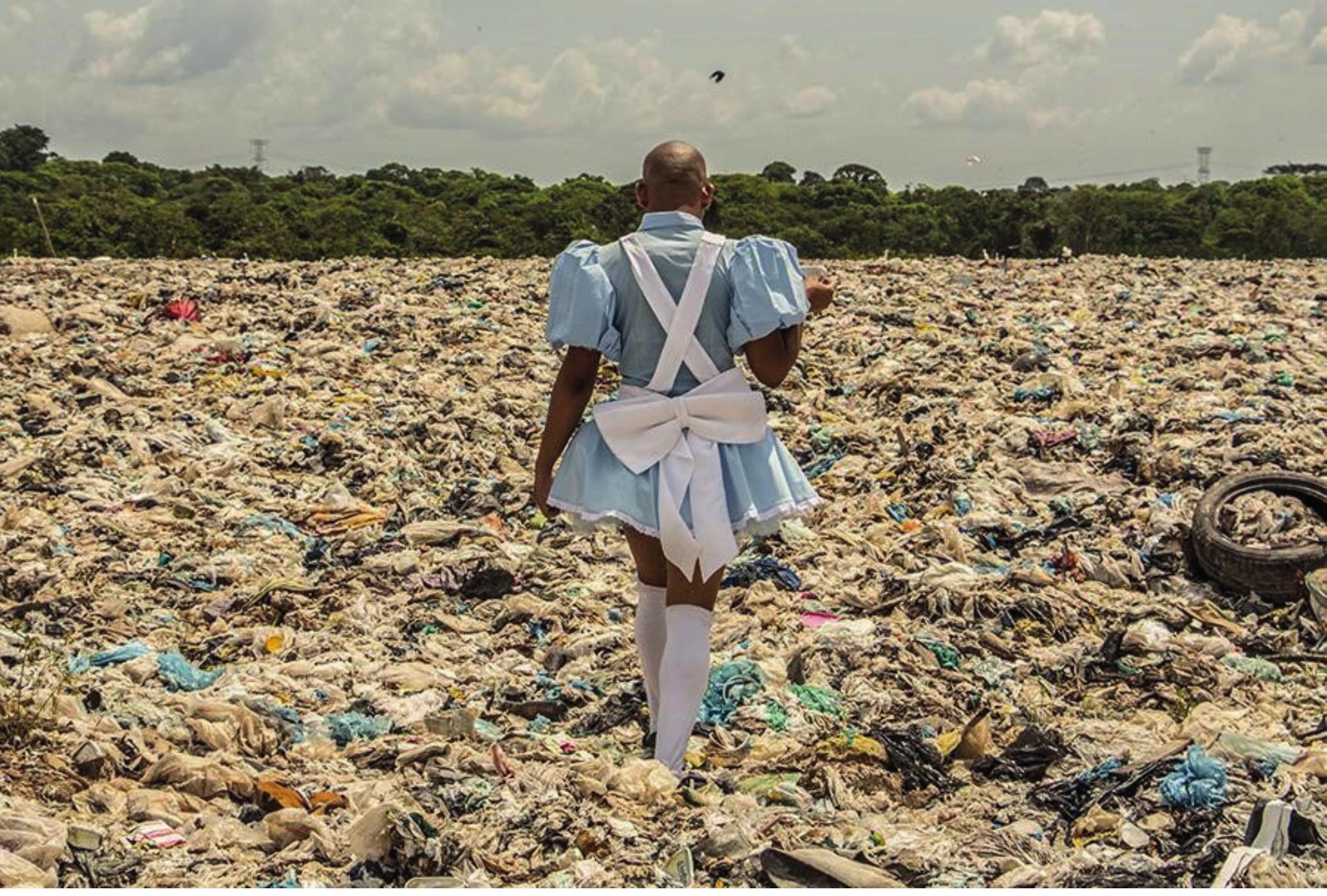

Figura 1: Alice, obra de Rafael Bqueer. Fonte: http://www.redbullstation. com.br/conheca-os-artistas-que-participam-da-14a-residencia-artistica/ alice/ 


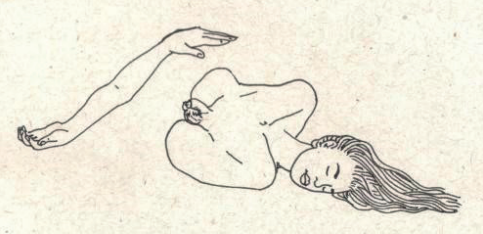

Figura 2: Desenhos de Tarcísio Gabriel. Fonte: http://tarcisiogabriel.tumblr.com/
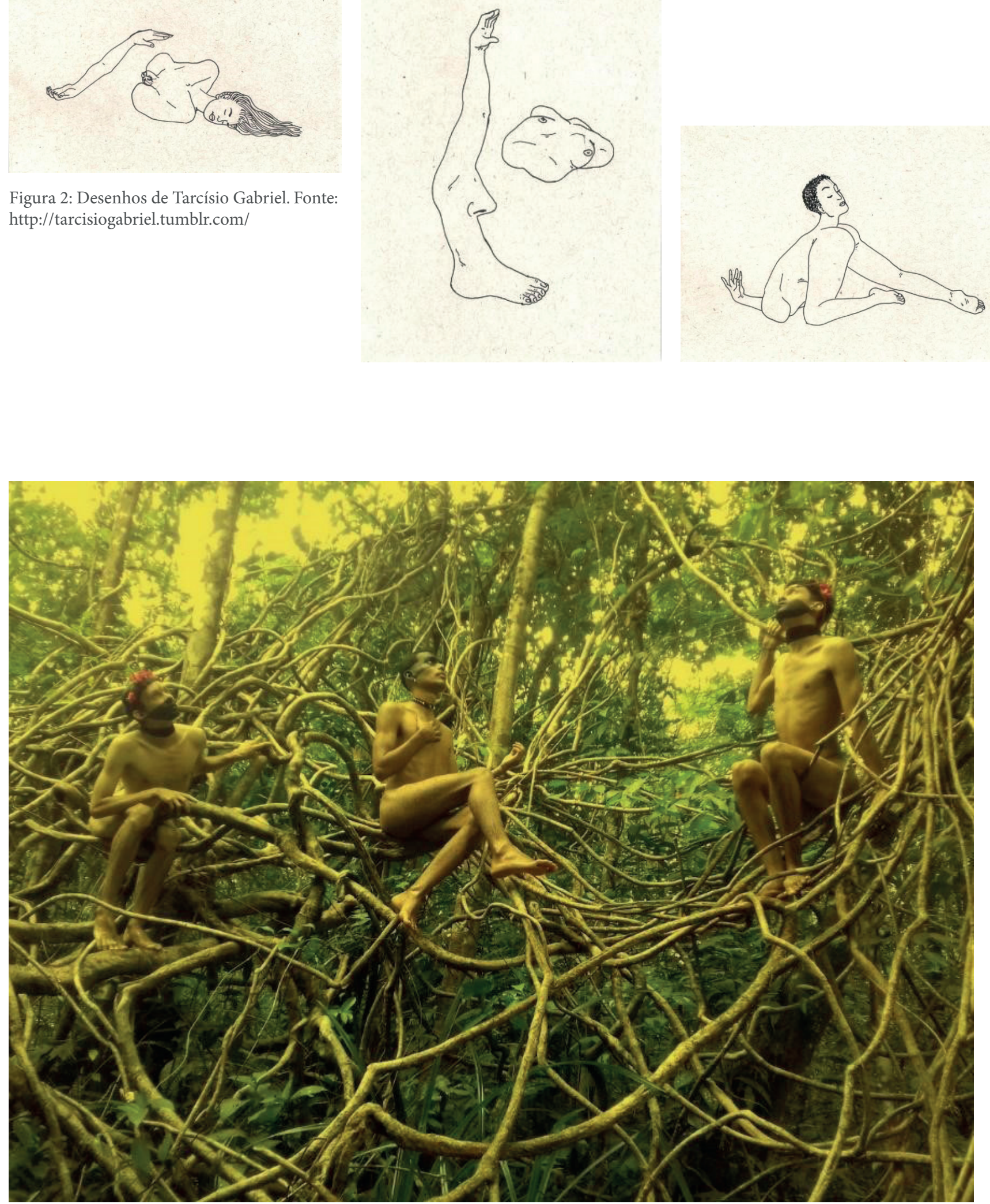

Figura 3. Fonte: Lucas Barros 
A fotografia e o desenho, mecânico e orgânico, foram abrindo possibilidades para a construção curatorial que guiaria o projeto.

Já tendo um arsenal bem consolidado de artistas com trabalhos que discutem identidade, gênero e sexualidade, não foi difícil selecionar as próximas imagens que fariam parte da exposição. O espaço Casulo Cultural já ser envolvido em circuitos de arte LGBTQ além de sediar eventos do Noite Suja, festa livre conhecida pela presença de drags, criava uma perfeita harmonia para o nascimento da expo CUIR.

\section{ALGUMAS DAS OBRAS SELECIONADAS: COMENTÁRIOS E REFLEXÕES}

A estranheza trash de Lucas Gouvea (Figura 4) foi impressa em jato de tinta, impressora comum. Suas cores saturadas gritam o absurdo, apresentam um entrelugar de experimentação, que em sua composição kitsch relembra a uma espécie de pastiche, uma paródia esvaziada (BUTLER, 2015, p.239).

\begin{abstract}
A perda do sentido do "normal", contudo, pode ser sua própria razão de riso, especialmente quando se revela que "o normal", "o original "é uma cópia, e, pior, uma cópia inevitavelmente falha, um ideal que ninguém pode incorporar. Nesse sentido, o riso surge como a percepção de que o original foi sempre um derivado. (BUTLER, 2015, p. 239)
\end{abstract}

A suposta estabilidade das construções de masculino e de feminino é colocada como categorias reguladoras da identidade. A subversão da norma gera fissuras ao assumir um lugar de reconhecimento ativo, e não mais fragilizado nas suas relações de poder e reconhecimento.

Romário em seu print de facebook (Figura 5) reconfigura sua apresentação cabana em um contexto digital, com suas margens de navegador e comentários a mostra, a experiência digital, de rolagem em linhas do tempo de uma rede social se fazem presente fora de seu espaço de origem, sem movimento ou possibilidade de ação, um frame recortado, trecho congelado de uma esfera tecnológica.

Como Pelúcio (2014, p. 5) coloca "Nem todo o saber foi expropriado, quero dizer a Preciado. Basta olhar para além da linha do Equador, para o 'cu do mundo'." O personagem amazônico cabano é flexível, quebra sua cintura, permite-se ser floresta, tirar leite do pau, brincar com a postura do homem violento, armado para o conflito, subverte a colonização em seu protagonismo símbolo de resistência.

O corpo imaculado que repousa na água azul oceano é atravessado pela mancha vermelha menstrual, tecido escultórico congelado pela fotografia (Figura 6). Uma Ophelia em suspensão.

A etnografia de Turner (2005) é uma boa análise do que as cores significam em uma sociedade. Ele reúne o que seus informantes aprenderam, através de ritos de vários tipos, sobre os significados das cores. O vermelho representa diversas categorias de sangue que agem para o bem e para o mal: sangue de animais derramado pelo caçador, sangue de parturição e menstruação, sangue do assassinato e da bruxaria. No caso da imagem de Sid Manequim, o vermelho é diretamente associado à violência metafórica, que corta o rio desmontando uma suposta calmaria do azul saturado que grita em uníssono com o vermelho em fluxo. 


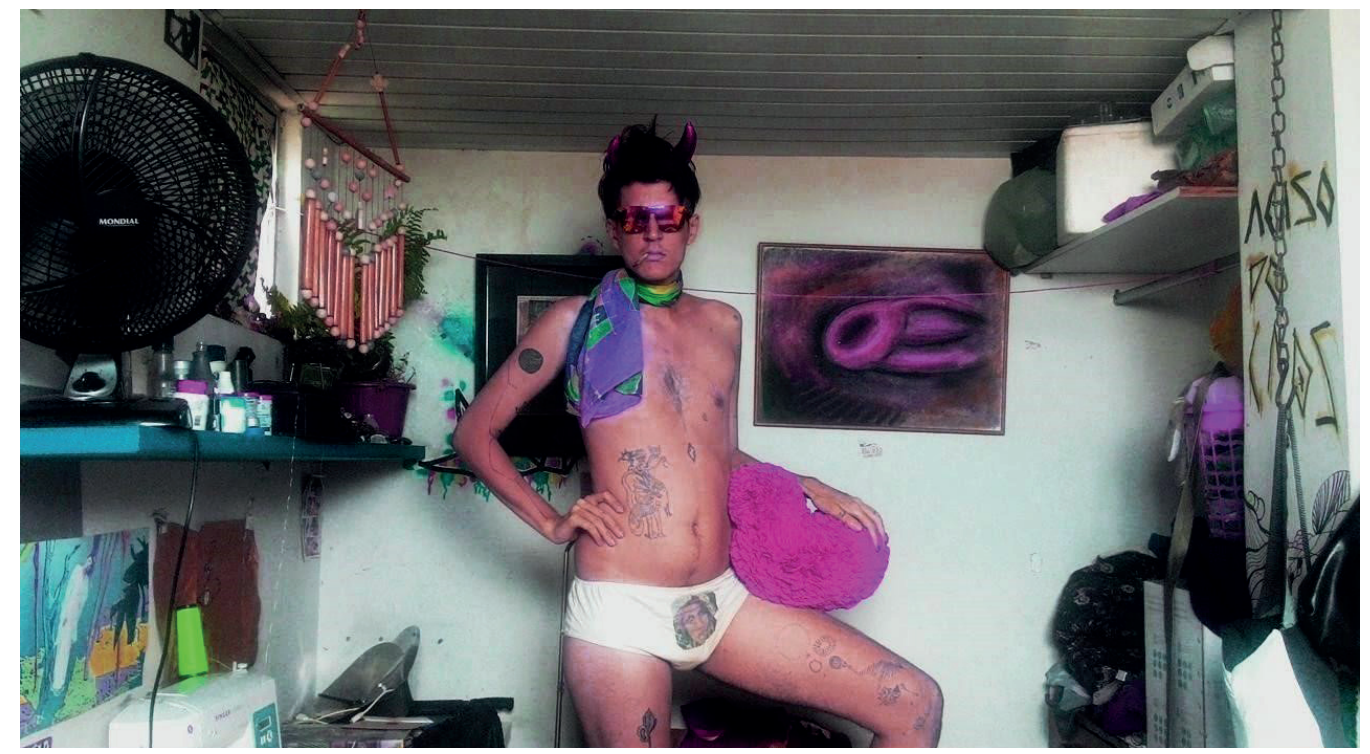

Figura 4. Fonte: https://www.facebook. com/lusssca

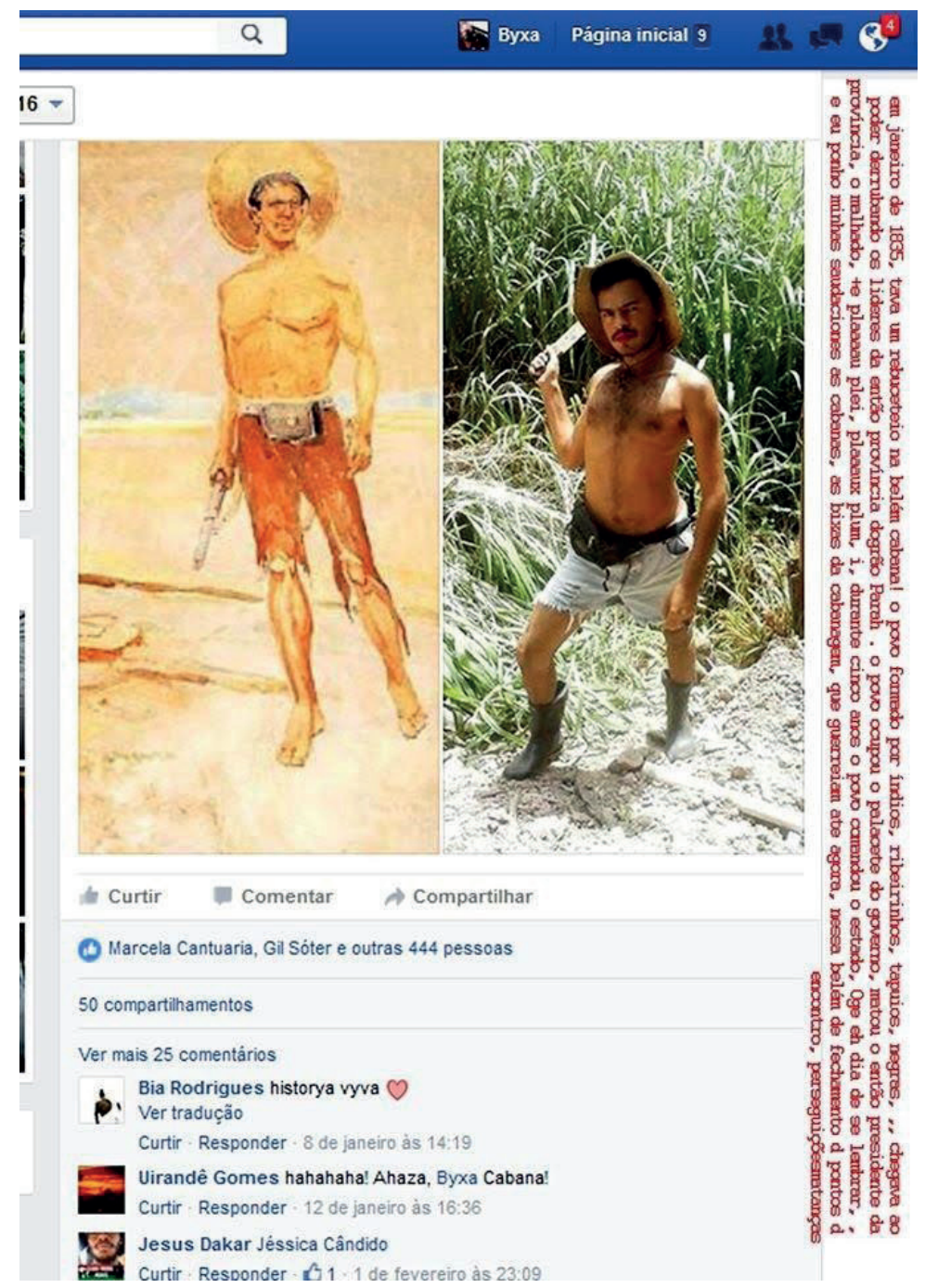




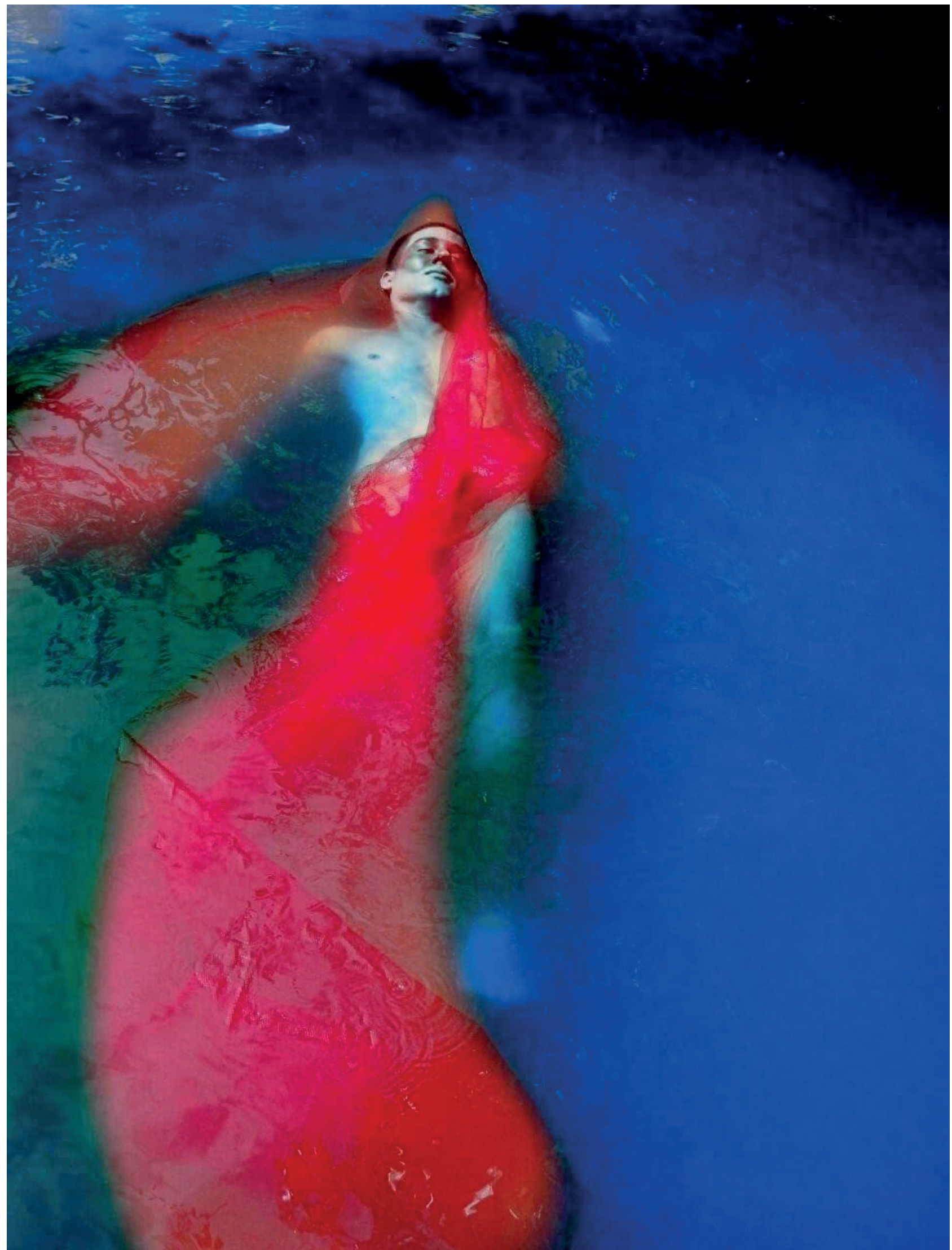

Figura 6: Natureza X, Sid Manequim. Fonte: https://www.facebook. com/sidmanequim2 
Duas reproduções próximas semelhantes. Dois retratos de rostos não binários. Cílios, maquiagem, barba, traços femininos e masculinos arranjados num mesmo rosto. Uma pintura em tela e um jpg feito no paint, cores no branco, Maitê Zara (Figura 7) e Flores Astrais (Figura 8). Buscar uma resposta definitiva para a questão "é homem ou é mulher?" não serviria de outra função se não de uma tentativa de resumir identidades a um genital, quando o caráter performativo do gênero é o centro da reflexão.

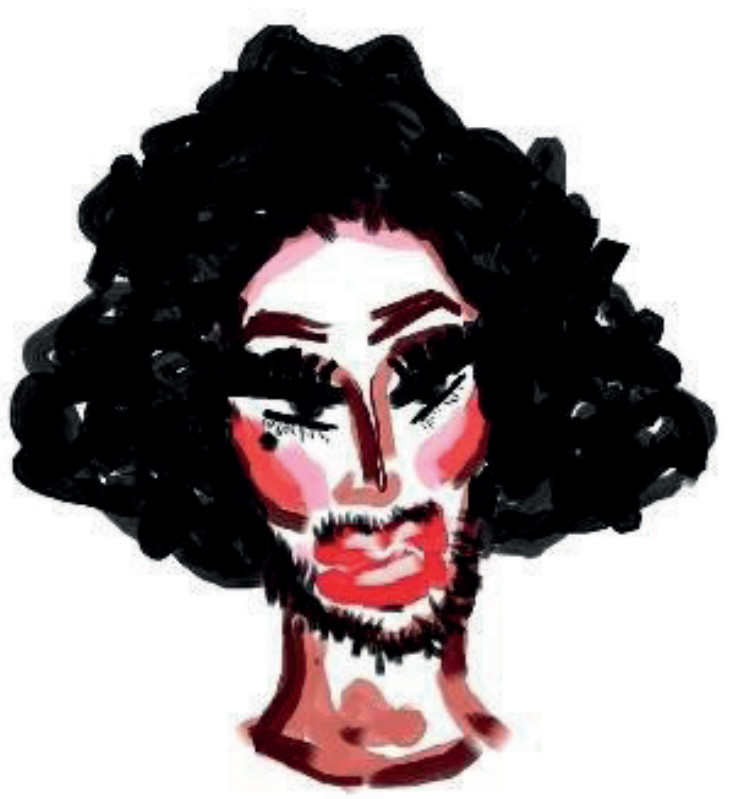

Figura 8: Flores Astrais no paint

Fonte: https://www.facebook. com/amaisbunita

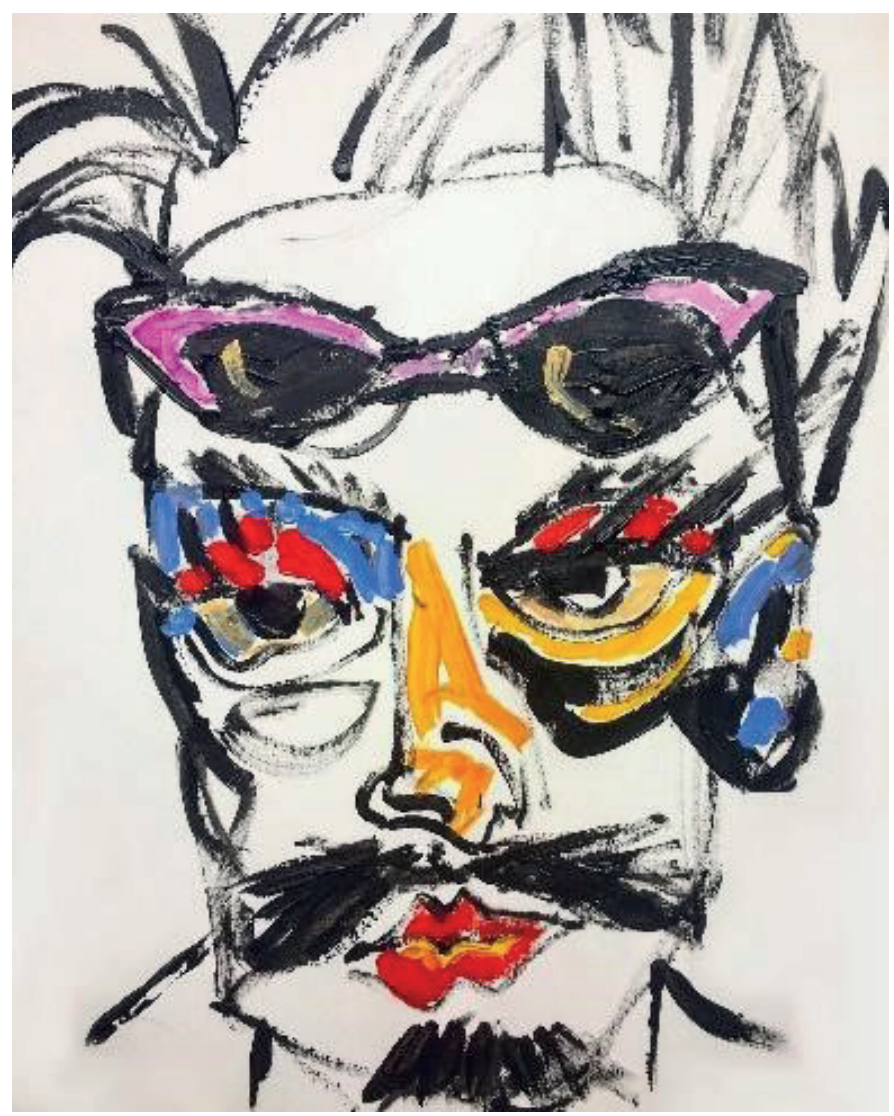

Figura 7: Pintura de Maitê. Fonte: Maitê Zara Gentil 
Outra imagem de Lucas (Figura 9) encara o espectador e o convida para entrar. Um varal com imagens penduradas brinca com a própria metalinguagem de uma exposição dentro de uma exposição, um espelho no quadro, uma câmera com o flash em direção ao espectador e ao próprio retratado.

Doppelgänger (Figura 10), fotografia de Lucas Barros apresenta dois gêmeos, que remetendo à lenda germânica de um duplo falso, questiona justamente a existência de um eu verdadeiro, ou de um gênero original, que é subvertido.

Penitência (Figura 11), performance de 2013 de Rafael Bqueer com registro de Marcia Ferreira, revela um corpo exposto ao desabamento, físico e social quando em meio a escombros oculta a face em vermelho e dialoga com o próprio espaço destruído.

Figura 9: Lucas Gouvea e o espelho. Fonte: facebook.com/ lusssca
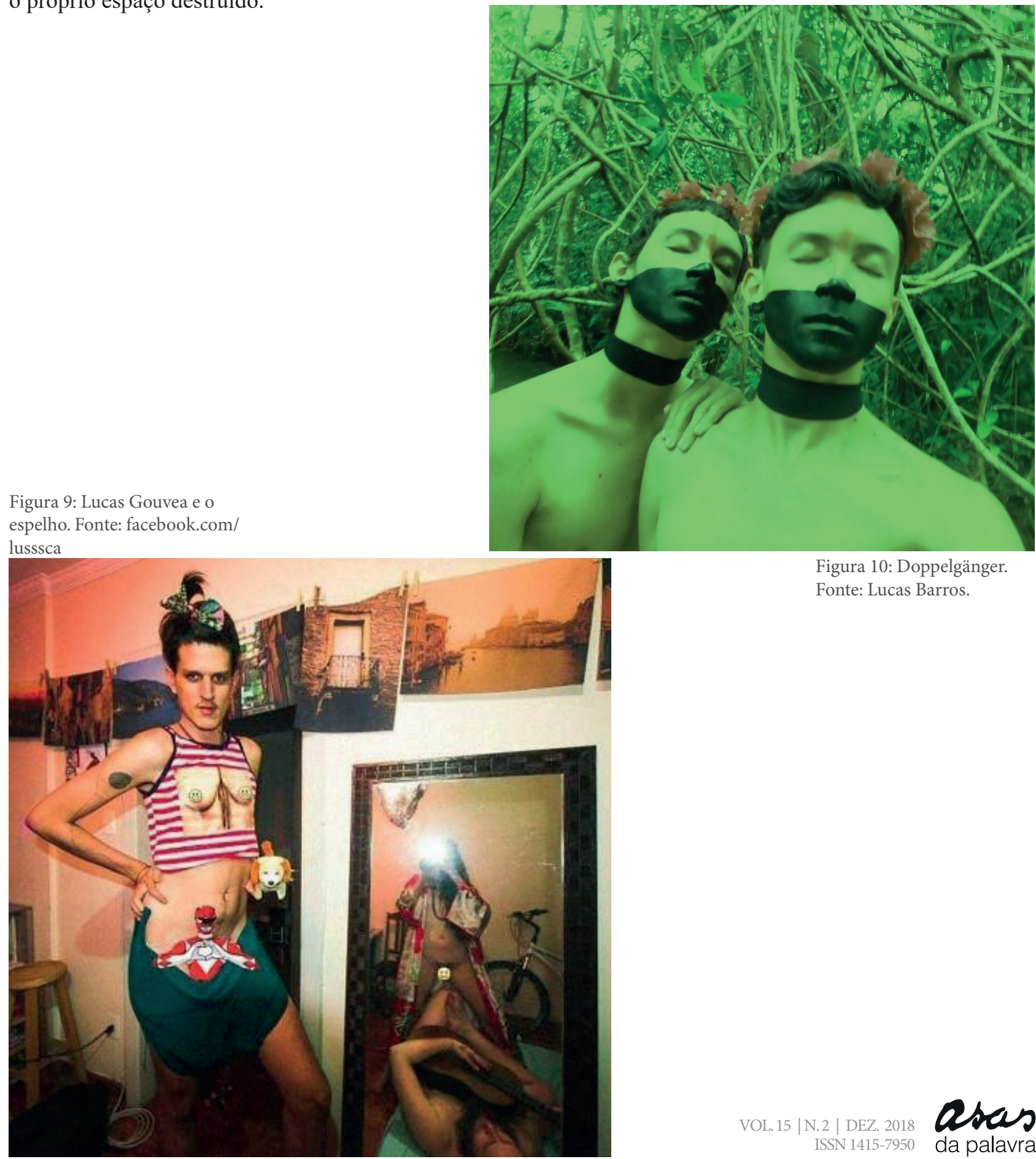

Figura 10: Doppelgänger. Fonte: Lucas Barros. 


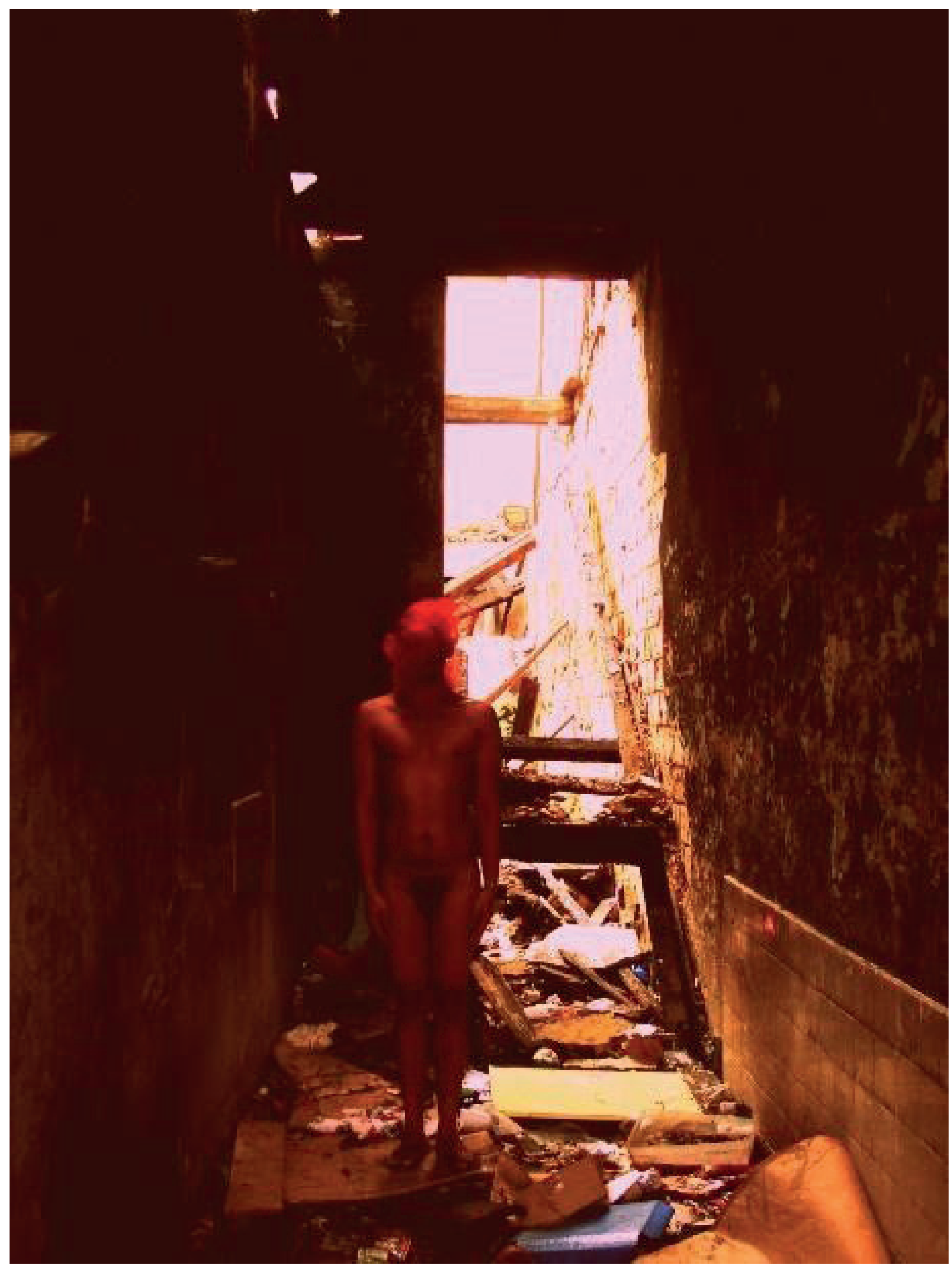

aras

da palavra
VOL. 15 | N.2 | DEZ.2018

ISSN 1415-7950
Figura 11: Rafael Bqueer,

Penitência. Fonte: rafael-bqueer. tumblr.com 


\section{CONSIDERAÇÕES FINAIS}

Como construir narrativas em arte CUIR de forma crítica e ao mesmo tempo horizontal diante tal trânsito epistemológico? A teoria CUIR aqui usada como proposta pedagógica é descentralizada e provocativa, tem o sujeito como protagonista do exercício de reflexão e inflexão em uma exposição de arte, mas olha para além do indivíduo, questionando as esferas dominantes de poder.

A experiência tornou clara como uma exposição artística pode reverberar para além de seus espaços físicos e atingir desdobramentos nem sequer esperados, como por exemplo, a entrevista concedida ao programa Sem Censura da TV Cultura com as falas de Renata Aguiar (dona do Casulo Cultural) sobre arte CUIR e suas possibilidades políticas.

A luta da arte contra a subordinação moral é a necessidade de se colocar como potência ativa e modificadora, atingindo progresso nas discussões de gênero e sexualidade sem aceitar o atual modelo que procura regular nossas vidas.

A vontade de mudança é apenas o princípio para se perceber além. Necessita comunicar, fazer-se entender com todas suas problemáticas, apresentar esse corpo estranho, subversivo, e ter os espaços ocupados por arte genuína, que coloca seu lugar no mundo.

\section{REFERÊNCIAS}

BUTLER, J. A journal of lesbian and gay studies. novembro, 1993

BUTLER, J. Problemas de gênero: feminismo e subversão da identidade. Rio de Janeiro, Civilização Brasileira, 2003.

LOURO, Guacira Lopes. Teoria queer: uma política pós-identitária para a educação. Rev. Estudos Femininos. [online]. vol. 9, n.2, p.541-553, 2001.

LOURO, Guacira Lopes. Um Corpo Estranho: Pedagogias da sexualidade. Belo Horizonte: Autêntica, 2004.

PELÚCIO, Larissa. Traduções e torções ou o que se quer dizer quando dizemos queer no Brasil? Revista Periodicus, v.1, n.1 maio-outubro, 2014.

PRECIADO, Paul Beatriz. Manifesto Contrassexual. Políticas subversivas de identidade sexual. São Paulo: n-1 edições, 2014.

TURNER, Victor. Floresta de Símbolos. Aspectos do ritual Ndembu. Niterói, RJ. Editora da Universidade Federal Fluminense. 2005.

SEDGWICK, Eve Kosofsky. Epistemology of the Closet. In: ABELOVE, Henry et alli. The lesbian and gay studies reader. New York/London, Routledge, p. 45-61, 1993.

Recebido em 04 Nov 2018 | Aprovado em 21 Nov 2018

Pedro Oliveira e Silva SAMPAIO

Artista e curador independente, bacharel e licenciado em Artes Visuais e Tecnologia da Imagem pela Universidade da Amazonia - UNAMA. Nascido em Florianópolis, reside em Belém do Pará onde participou de exposições como Premio Diario Contemporaneo de Fotografia, Primeiros Passos do CCBEU e MOAV - UNAMA. Em 2017 organizou e curou a exposiçao CUIR no Espaço Casulo Cultural.

Simone de Oliveira MOURA (orientadora)

Mestre em Artes pelo PPGArtes da Universidade Federal do Pará (2013), Bacharel e Licenciada em Artes Visuais e Tecnologia da Imagem pela Universidade da Amazônia (2005). É professora da SEDUC/PA. Foi docente da UNAMA de 2014 a 2018 e do PARFOR (UFPA/ARTES VISUAIS) de 2012 a 2015. Em 2013 foi Júri de Seleção e Premiação do já extinto $19^{\circ}$ Salão Unama de Pequenos Formatos. Foi bolsista pesquisadora em Programas de Educação Patrimonial pelo Museu Paraense Emílio Goeldi. Tem experiência na área de Educação, com ênfase em Educação Patrimonial e Fotografia. E-mail: simoneoliver2@hotmail.com 